\title{
Comparison study for some biomechanical and physiological variables as a indicates for passing admission tests for the physical education department at AL Qaseem and Port Said University
}

\author{
DR. Hani Abd Aziz Salah
}

\section{1/0 Introduction:}

Physical tests are considered the first criterion for admission to colleges and departments of physical education, whether in the Arab Republic of Egypt or the Kingdom of Saudi Arabia, and the student who wishes to join them must first pass many tests. Appendix (1) (2)

Work, energy and power are among the most important biodynamic variables for kinetic performance, as patton, C (2018) (18) and Barlett refer. R. Bartlett, R (2007) (3) that work is how energy is transmitted from one body to another, while energy is defined as the power to perform work, while power is defined as the rate of labor.

From the above, it is clear that the conjugation of work, energy, and power gives an indication of its relation, concept, definition, and law.

.Bagchi, D et al. (2013) (1) Daries, H, and Haff. C et al. (2012) (6) are point to The energy systems in the human body are divided into two basic systems which are the anaerobic system and the antenna system, and that metabolism is closely related to the power of muscles to contract and thus to the ability to do work.

Where both W. W. Hawkins, Winsettel. M (2013) (16) Nestle, M, and Max Kleiber (2013) (16) that the direct relationship between joules and calories is explained by the formula (1 calorie $=4.184$ joule), which emphasizes the direct relationship between calories and joules, that is, whenever The more work or energy spent the higher the calorie consumption.

From the above, it can be said that the biomechanical variables understudy of labor, energy, and power can be inferred from the rate of calorie consumption during the athletic activity, as shown by the equation ( 1 calorie $=4.184$ joule), which confirms the mechanical basis by which physiological variables such as the rate of consumption can be inferred Calories.

\section{2/0 Research importance and problem:}

Through the researcher's work on admission tests in the College of Physical Education in Port Said, the Arab Republic of Egypt, and the Department of Physical Education and Movement Science at the University of Al-Qassim in the Kingdom of Saudi Arabia, he noted that the percentage of those who did not pass the applicants exceeded 70\%, and the researcher also noted that there were some cases of vomiting or a sense of dizziness Among some of the presenters, the researcher attributes this to the fact that the wrong diet followed by some applicants and the lack of awareness of the applicant with the physical effort that he will have during the performance of the tests may be one of the reasons for not passing, and that in the case of full knowledge of the physical effort that will fall on the subject Blood before starting the tests may have a positive effect on passing the tests, especially the physical ones.

The importance of the study appears in determine the calories required to pass the admission tests in the Department of Physical Education and Movement Science, as well as the calories required to pass the admission tests in the colleges of physical education in the Arab Republic of Egypt and the Kingdom of Saudi Arabia to give the applicants a prior background on 
the number of calories consumed during the performance of the tests, as it works on To give a complete perception of the physiology of calorie consumption and thus the most appropriate diet and appropriate intermission periods for hospitalization and restoration of the diet to its ability to produce the required energy.

The importance of the practical study also appears in determining the amount of work spent, energy, and power spent during the performance of the tests, which may help to give a complete background to the applicant before starting the tests for admission, especially the physical ones, as the greatest effort exerted during admission tests is during physical tests, and given the multiplicity And the great diversity in the skills chosen by the applicants and the difficulty of restricting them, so the researcher studied the biodynamic variables and calories during physical tests without taking into account the variables of the rest of the tests.

The study also gives a clear picture of the biodynamic variables and calories that may be a scientific basis for restructuring the physical tests for admission to the colleges of physical education in the Arab Republic of Egypt and Saudi Arabia.

The study also aims to compare the colleges of physical education in the Arab Republic of Egypt and the Kingdom of Saudi Arabia in the variables of work, energy, and calories to transfer benefits in the two countries and develop admission tests in each of them.

\section{3/0 Research Goals:}

This study aims to explain and study the phenomenon of bilateral disability of the upper end during weight training from the standpoint of biomechanics through:

3/1 Determine the number of energy spent during the performance of the acceptance tests. $3 / 2$ Determine the number of Work spent during the performance of the acceptance tests.

$3 / 3$ Determine the number of Power spent during the performance of the acceptance tests. 3/4 Determine the number of Calories spent during the performance of the acceptance tests.

\section{4/0 Research Hypothesis:}

4/1 how much Energy was spent during the acceptance tests?

$4 / 2$ how much Work was spent during the acceptance tests?

$4 / 3$ how much Power was spent during the acceptance tests?

4/4 how much Calories was spent during the acceptance tests?

\section{5/0 Research Procedures:}

\section{5/1 Research Methodology}

the study.

The researcher used the descriptive method using the survey method to suit the nature of

\section{5/2 Research Simple:}

The primary study sample was chosen in the intentional method from the applicants for admission in the Department of Physical Education and Movement Science in Saudi Arabia, as well as from the applicants for admission to the Faculty of Physical Education in Egypt for the academic year 1439/1440 corresponding to 2018/2019, and the study population included (1200) applicants, and (700) were excluded. Applicants did not pass the exams successfully, and (300) applicants whose physical exams were below average were excluded so that the number of the study sample is (100) advanced to join the Department of Physical Education and Movement Science in Saudi Arabia, and (100) applicants to join the College of Physical Education in Egypt. 
Table 1. The Description of research sample $(n=200)$

\begin{tabular}{|c|c|c|c|c|c|c|c|c|c|c|}
\hline & \multicolumn{4}{|c|}{ Saudi Arabia } & \multicolumn{4}{|c|}{ Egypt } \\
\hline & & & $\begin{array}{c}\text { Measure } \\
\text { ment } \\
\text { Unit }\end{array}$ & Mean & $\begin{array}{l}\text { standard } \\
\text { deviation }\end{array}$ & $\begin{array}{c}\text { torsion } \\
\text { coefficie } \\
\mathrm{nt}\end{array}$ & $\begin{array}{c}\text { Measure } \\
\text { ment } \\
\text { Unit }\end{array}$ & Mean & $\begin{array}{c}\text { standard } \\
\text { deviation }\end{array}$ & $\begin{array}{c}\text { torsion } \\
\text { coefficie } \\
\text { nt }\end{array}$ \\
\hline \multirow{3}{*}{$\begin{array}{c}\text { Growth } \\
\text { rates }\end{array}$} & 1 & Tall & $\mathrm{Cm}$ & 172.7 & 3.97 & 0.473 & $\mathrm{Cm}$ & 216.48 & 7.22 & -0.169 \\
\hline & 2 & Wight & $\mathrm{Kg}$ & 64.12 & 7.4 & 1.64 & $\mathrm{Kg}$ & 60.50 & 1.29 & 0.694 \\
\hline & 3 & Age & Month & 220.8 & 10.23 & 3.00 & Month & 174.68 & 3.34 & -0.692 \\
\hline \multirow{6}{*}{$\begin{array}{c}\text { Physica } \\
1 \text { tests }\end{array}$} & 1 & $\begin{array}{c}\text { maximum } \\
\text { speed }\end{array}$ & $\mathrm{Sec}$ & 7.24 & 0.277 & -1.00 & Sec & 12.41 & 0.11 & -0.846 \\
\hline & 2 & $\begin{array}{l}\text { Endure } \\
\text { strength }\end{array}$ & Number & 22.36 & 4.61 & -1.264 & Number & 13.00 & 1.50 & -0.812 \\
\hline & 3 & Power & $\mathrm{Cm}$ & 204.99 & 8.40 & -0.250 & $\mathrm{Cm}$ & 221.00 & 7.91 & -1.388 \\
\hline & 4 & Agility & $\mathrm{Sec}$ & 6.14 & 0.232 & -0.826 & Number & 34.300 & 1.16 & -0.484 \\
\hline & 5 & Flexibility & $\mathrm{Cm}$ & 10.36 & 4.02 & -0.898 & $\mathrm{Cm}$ & 18.20 & 1.92 & -0.212 \\
\hline & 6 & Endurance & $\min$ & 2.01 & 0.277 & -0.320 & $\min$ & 2.16 & 0.02 & -0.069 \\
\hline
\end{tabular}

From Table (1) it is clear that the values of the torsion coefficient for each of these variables (understudy) have been limited to $( \pm 3)$, which indicates the moderation of the iterative curve of the study sample in these variables.

\section{5/3 Data collection tools:}

5/3/1 Biomechanics Data collection tools:

Capture, 3D Video by Gopro hero4 black Camera (240fbs)

- Calibration cube $2 * 2 * 1$

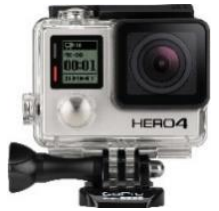

Figure (1) Gopro hero4 black

Table 2. Dimensions of the calibration cube

\begin{tabular}{c|c|c|}
\hline \hline & Camera 1 & Camera 2 \\
\hline \hline Camera distant from cube & $6.73 \mathrm{~m}$ & $6.73 \mathrm{~m}$ \\
\hline Camera height & $1.35 \mathrm{~m}$ & $1.35 \mathrm{~m}$ \\
\hline Distant between cameras & \multicolumn{2}{|c|}{$4.15 \mathrm{~m}$} \\
\hline Camera`s angle & $90^{\circ}$ & $90^{\circ}$ \\
\hline \hline
\end{tabular}

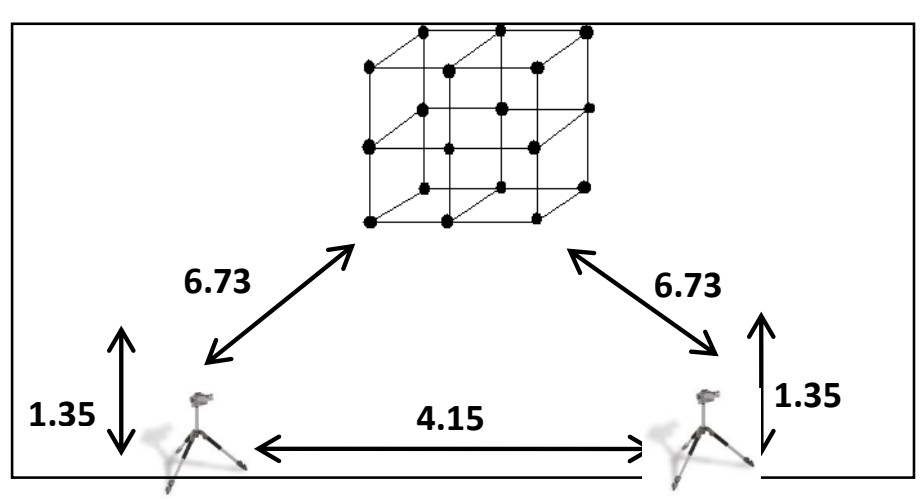

Figure (2) Dimensions of the calibration cube

\section{5/3/3 Anthropometric Data collection tools}


The methods and tools for data collection that are appropriate to the nature of the study were identified by looking at the scientific references, researches, and previous studies.

- Restmeter to measure the total length of the body.

- Medical balance device to measure the mass of the player.

\section{5/4 Pilot Study:}

The researcher conducted a pilot study to identify the conditions and problems that may face the researcher during the basic study and was implemented on Tuesday 5/5/2019 at Al Qaseem University Sports hall Saudi Arabia. The survey was conducted on (1) players, the survey aimed to identify:

- Dimensions for cameras.

- Visibility through cameras to facilitate later analysis.

And the pilot study achieved its objectives.

\section{5/5 Basic study:}

The basic study was carried out on Thursday 6/5/2019 to 9/5/2019 at Al Qaseem University Sports hall Saudi Arabia. And on

\section{5/6 Statistical Treatments}

The researcher used the program (Statistical Package for Social Science) (SPSS 20) (Statistical Package for Social Science) in the processing of data statistically using the appropriate statistical coefficients of the study.

\section{6/0 Results:}

\section{6/1 Present the results:}

In the following, the results of the study are presented and discussed by using the employment, energy, power and calories index as determinants to pass the acceptance tests, in light of the data and results of the measurements of the variables under study on the sample and based on the results of the statistical analysis that are in line with the nature of the current study. In light of the hypotheses of the study, the researcher will present his findings as follows:

6/1/1 Presentation of the data of the variable energy spent, work, power, and calories while performing physical tests:

Table 3. Average energy spent, work, power, and calories while performing physical tests

\begin{tabular}{c|c|c|c|c|c|c|c|c|c}
\hline \multirow{2}{*}{\multicolumn{2}{c|}{ Item }} & \multicolumn{2}{c|}{ Calories (Cal) } & \multicolumn{2}{c|}{ Power (joule/sec) } & \multicolumn{2}{c|}{ Work (joule) } & \multicolumn{2}{c|}{ Energy (joule) } \\
\cline { 2 - 10 } & Egy & Sud & Egy & Sud & Egy & Sud & Egy & Sud \\
\hline \hline 1 & maximum speed & 469.85 & 366.35 & 158.42 & 212.44 & 1965.88 & 1532.84 & 1965.88 & 1532.84 \\
\hline 2 & Endure strength & 35.29 & 63.98 & 147.69 & 267.72 & 4430.7 & 8031.70 & 4430.7 & 8031.70 \\
\hline 3 & Ability & 35.39 & 39.35 & 113.91 & 126.65 & 148.09 & 164.64 & 148.09 & 164.64 \\
\hline 4 & Agility & 13.15 & 66.015 & 1.56 & 45.13 & 55.0 & 276.21 & 55.0 & 276.21 \\
\hline 5 & Flexibility & 0.011 & 0.0122 & 0.047 & 0.0511 & 0.047 & 0.0511 & 0.047 & 0.0511 \\
\hline 6 & Endurance & 272.52 & 204.90 & 8.74 & 7.11 & 1140.26 & 857.32 & 1140.26 & 857.32 \\
\hline \hline
\end{tabular}

It is clear from Table (3) the angles of the body under study, where it is clear that the degrees of the tilt angle of the sides of the work of the individual and bilateral muscle ranged between (91.8 - 74.5) during the three phases of performance, and the degrees of the tilt angle of the front and back of the work of the individual muscle and bilateral ranged between (93.8 During 
the three performance phases, elbow angle degrees for individual and bilateral muscular work ranged from 165.3 - 148.6 during the first phase, 95.2 - 88.0 during the second phase, and 54.6 48.1 during the third phase. The degrees of free arm angle for individual muscular work ranged between (44.2 - 46.3) during the first phase, and (45.6) - 46.9) during the second phase, (68.8 66.8) during the third phase.
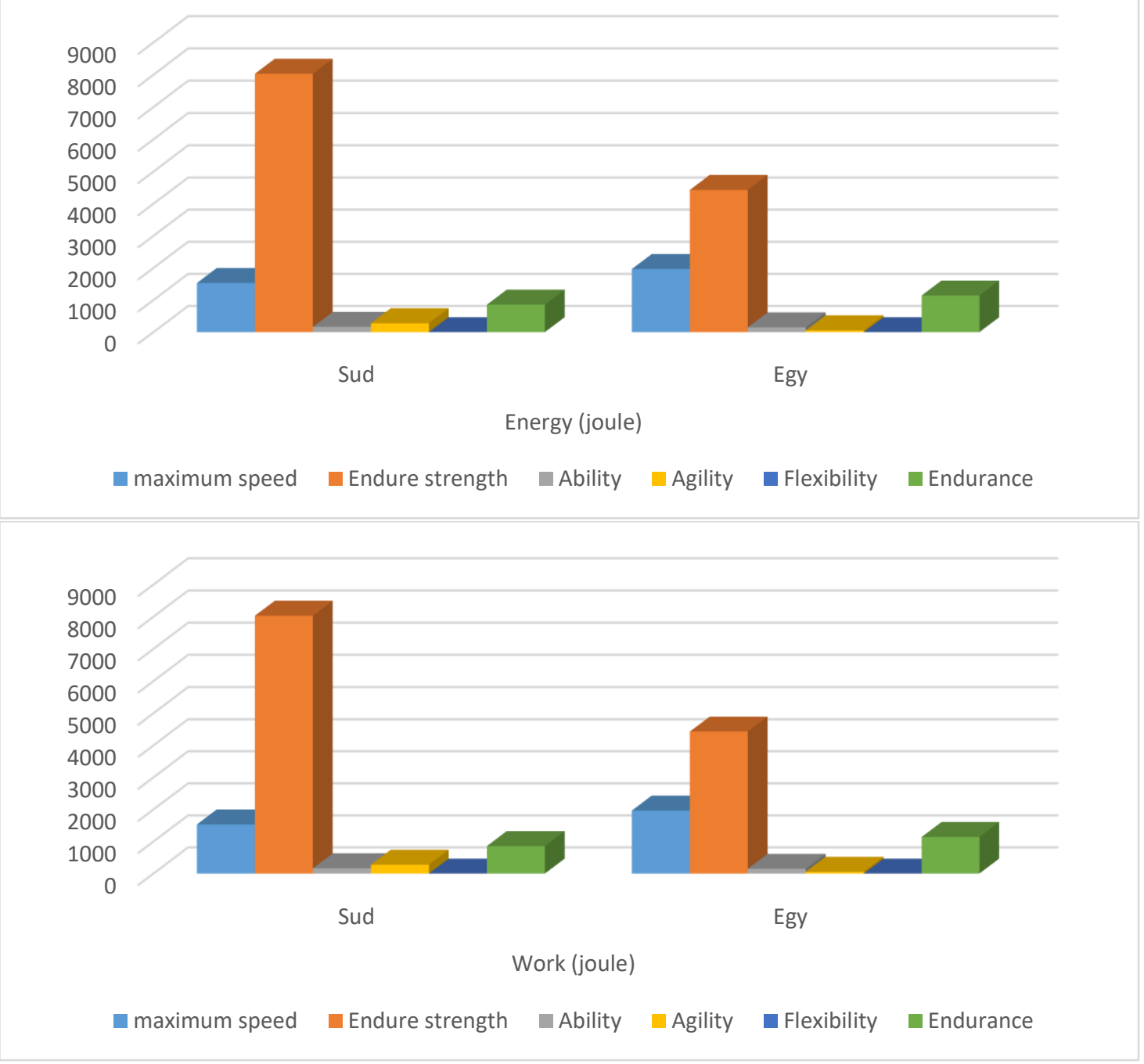


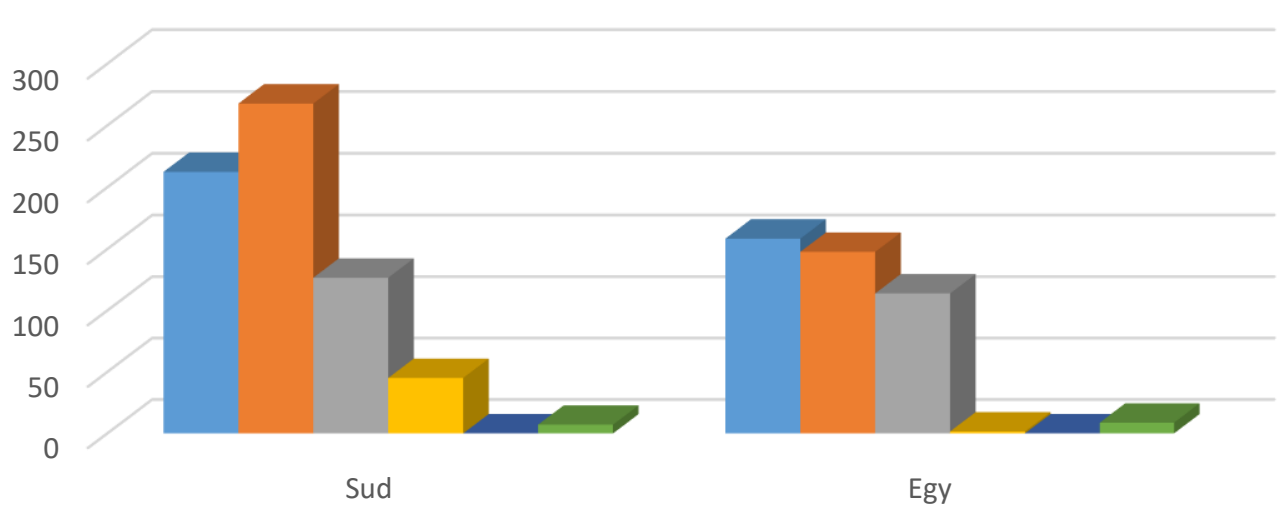

Ability (joule/sec)

maximum speed Endure strength Ability Agility $\square$ Flexibility Endurance

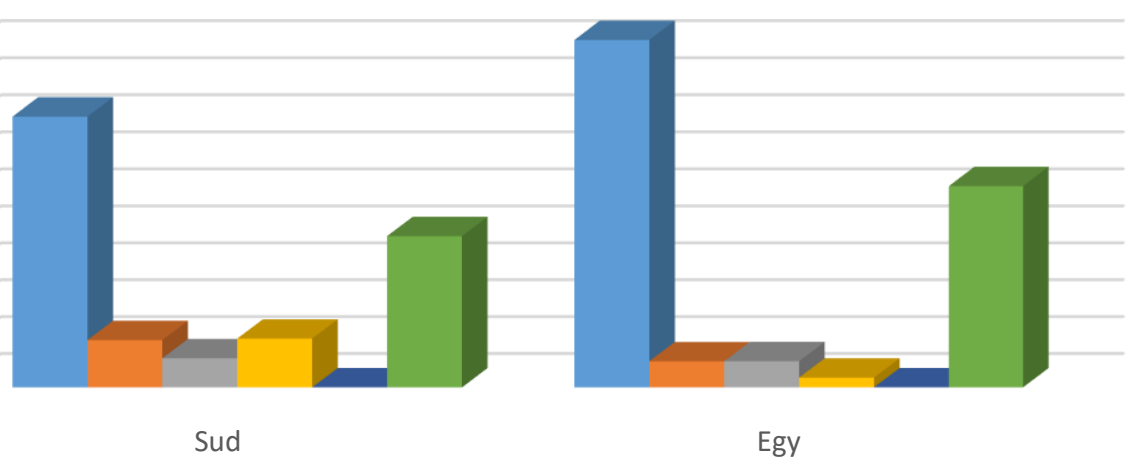

Calories (Cal)

maximum speed Endure strength $\square$ Ability Agility $\square$ Flexibility Endurance

Figure (1) Average energy spent, work, power, and calories while performing physical tests

6/1/2 Presentation of the data of the order of the tests according to the variables of energy, work, power, and calories while performing the physical tests:

Table 4. Arrange the tests according to the variables of energy, work, power and calories

\begin{tabular}{c|c|c|c|c|c|c|c|c|c}
\hline \multirow{2}{*}{\multicolumn{2}{c|}{ Item }} & \multicolumn{2}{c|}{$\begin{array}{c}\text { order according to } \\
\text { Calories }\end{array}$} & $\begin{array}{c}\text { order according to } \\
\text { Power }\end{array}$ & \multicolumn{2}{c|}{$\begin{array}{c}\text { order according to } \\
\text { Work }\end{array}$} & \multicolumn{2}{c}{$\begin{array}{c}\text { order according to } \\
\text { Energy }\end{array}$} \\
\cline { 2 - 11 } & Egy & Saud & Egy & Saud & Egy & Saud & Egy & Saud \\
\hline \hline 1 & maximum speed & first & first & first & second & second & second & second & second \\
\hline 2 & Endure strength & fourth & fourth & second & first & first & first & first & first \\
\hline 4 & Ability & third & Fifth & third & third & fourth & Fifth & fourth & Fifth \\
\hline 5 & Flexibility & Sixth & Sixth & Sixth & Sixth & Sixth & Sixth & Sixth & Fifth \\
\hline 6 & Endurance & second & second & fourth & Fifth & third & third & fourth \\
\hline \hline
\end{tabular}


It is clear from Table (3) the angles of the body under study, where it is clear that the degrees of the tilt angle of the sides of the work of the individual and bilateral muscle ranged between (91.8 - 74.5) during the three phases of performance, and the degrees of the tilt angle of the front and back of the work of the individual muscle and bilateral ranged between (93.8 During the three performance phases, elbow angle degrees for individual and bilateral muscular work ranged from 165.3 - 148.6 during the first phase, 95.2 - 88.0 during the second phase, and 54.6 48.1 during the third phase. The degrees of free arm angle for individual muscular work ranged between (44.2 - 46.3) during the first phase, and (45.6) - 46.9) during the second phase, (68.8 66.8) during the third phase.

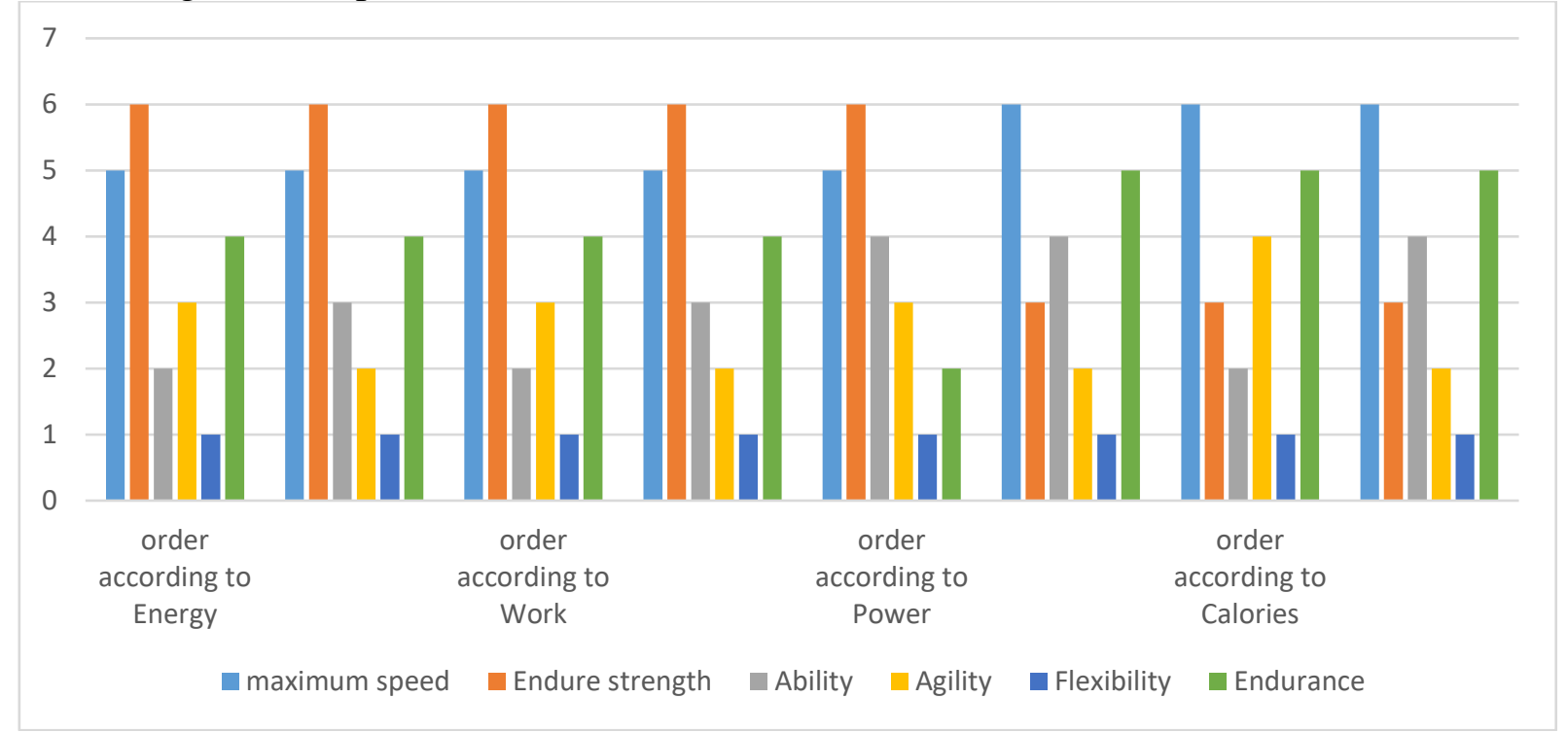

Figure (1) Arrange the tests according to the variables of energy, work, power and calories

\section{6/2 Discussion of the results:}

\section{6/2/1 Discussion of the results of the first Question:}

It is clear from Table (3) the amount of energy spent during the performance of physical tests for admission in Saudi Arabia, where it ranged between (8031.7 Joules) to test the strength tolerance, and between ( 0.0511 Joules) to test the flexibility, and the arrangement of energy spent ascending to the flexibility test by ( 0.0155 Joules) followed by the ability test With a value of (164.64 Joules), followed by the Agility Test with (286.21 Joules), followed by a leather test with (857.32 Joules) followed by the Enemy Test of $50 \mathrm{~m}$ (1532.84 Joules) and finally a test of strength bearing with (8031.7 Joules), and that the total energy expended amounted to (10862.76 Joules).

It is clear from Table (3) the amount of energy spent during the performance of physical tests for admission to Egypt, as it ranged between (4430.7 Joules) for the strength endurance test and between ( 0.047 Joules) for the flexibility test, and the arrangement of the energy spent ascending the flexibility test by ( 0.0155 Joules) followed by the agility test With a value of (55.0 Joules) followed by the ability test with (148.09 Joules), followed by a endurance test with (1140.26 Joules) followed by a speed test (1965.88 Joules) and finally a strength test with (4430.7 Joules), and that the total energy expended amounted to (7739.97 Joules).

Where Shamus, E. editor, \& Shamus, J. editor. (2017), indicate that the kinetic energy is calculated by the formula $\left(\mathrm{KE}=1 / 2 \mathrm{~m} \cdot \mathrm{v}^{2}\right)$. It is what has been applied in the testing of speed, ability, agility, flexibility, and endurance.

Also, the energy of the situation is calculated by the formula $\left(\mathrm{PE}=\mathrm{mg}^{*} \Delta \mathrm{x}\right)$, which was applied in the strength tolerance test. 
The researcher attributes this to the fact that the energy is directly related to the speed, so it appears that the amount of energy expended in the strength tolerance test was calculated by calculating the energy of the PE mode and dividing it by time, which caused the increase of the energy expended during the 30th period which is the test performance time.

It is also clear from Table (3) that the speed test is a measure of the maximum transitional speed of the applicant, so it ranked second in the rate of energy spent to perform physical tests, where the player performs the test from the low start and continues to run in a straight linear manner to the finish line without any change in The direction of movement is thus without a loss in the energy expended.

It is also clear from Table (3) in the endurance test that the amount of energy spent occupied the third position, amounting to (857.32 joules), although the speed of the applicant was not great, but continuing to do work for a distance of $600 \mathrm{~m}$, which in turn led to the increase in the energy spent during the test.

As shown in Table (3) in the agility test, which the player is supposed to perform at full speed, there is a significant decrease in the energy spent to perform the test, as it reached (276.21 joules). The researcher attributes this to the fact that the rotation stage around the last funneled to a great speed loss, which is consistent With the study of Hani Abdulaziz (2016) (8) in that the rotation around the vertical axis during the performance of agility tests greatly reduces horizontal velocity, which affects the degree of the test and the calculated biodynamic variables.

What is clear from Table (3) that the ability and flexibility test ranked fifth and sixth in the order of energy spent, as the average energy spent ( 164.64 joules $),(0.015$ joules) respectively, and the researcher attributes that to the movement in performing the ability and flexibility test is a single movement That is, it performs only once, unlike the previous tests, as it is either a repetitive movement such as a speed test, endurance and strength tolerance, or it is a vehicle like a fitness test.

In agreement with D, Jordan Robertson et al. (2004) (2) in that only motion consumes less energy because it depends on doing a one-time work without returning in the same kinematic path as strength testing, or it repeats the same form of performance more From time like speed and endurance test.

\section{6/2/1 Discussion of the results of the second Question:}

It is clear from Table (3) and (4) that the amount of work spent and the energy spent to match the researcher, and the researcher attributes this to the fact that the energy is the ability to do work, and it has been proven in mathematical equations that the amount of work done and the energy spent match either in kinetic energy or the energy of the situation.

In agreement with Pascolo, P.B. (2014) (17).

\section{6/2/1 Discussion of the results of the third Question:}

The researcher attributes this to the fact that these two tests require performing the maximum speed in the least time and that the movement in each of them was repetitive so the laboratory must perform the maximum ability it has to pass these two tests.

Where the power is calculated by the formula $(\mathrm{P}=\mathrm{W} / \Delta \mathrm{t})$

$$
\begin{aligned}
& P=\text { Power } \\
& W=\text { Work } \\
& t=\text { time }
\end{aligned}
$$

It is also clear from Table (5) that the power test has occupied the third position by $(126.65$ joules per second), and the researcher attributes this to that the amount of work done was divided 
by a relatively small time which is the flight time up which was an average of about (1.3 seconds), which Increased ability to perform this test.

It is also clear from Table (5) that each of the agility tests occupied the fourth position by (45.13 joules per second), which is the same arrangement in the amount of energy and work spent during the performance of the test.

The researcher attributes this to the loss of speed that was mentioned in the discussion of the first question and the accident in the rotation stage about the last funnel, which led to a great speed loss, which in turn affects the degree of testing and calculated dynamics.

It is also clear from Table (5) that the amount of urinal power in the endurance test has occupied the fifth position, that is, it has changed from its arrangement in Table (3), (4) The researcher attributes this to that despite the great work being done in performing this test, but that, according to calculate the power calculation, the amount of work spent is divided by the time taken to perform this test, which is the reason for the relative decrease in the amount of energy spent.

It is also clear from Table (5) that the elasticity test occupied the sixth position by $(0.0511$ joules per second), which is the same amount of energy and work spent in Tables (3) and (4), and the researcher attributes this to the fact that the performance of the test requires the stability of the laboratory in a maximum position Flexibility for $1 \mathrm{sec}$. By dividing the work and energy spent by $1 \mathrm{sec}$, we are given the same value for labor and energy

\section{6/2/1 Discussion of the results of the fourth Question:}

It is clear from the results of Table (6) that the calories consumed during the performance of the speed test reached $(366.35 \mathrm{Cal})$ while in the endurance test reached $(204.9 \mathrm{Cal})$ and the researcher attributes that to the body during the performance of the speed test depends on two types of anaerobic energy production systems (Anaerobic system) They are:

Muscle ATP consumption.

Phosphate System.

Lactic Acid System.

But it does not transfer to the oxygen system, which depends on oxygen for energy production because the test does not last more than (9th), which leads to the production of fast calories and their rapid consumption as well.

Consistent with Patchi. D Bauchi (2013) (1), Haff. C. Et al. (2008) (7), Daris. E, H. (2012) (6), McTiernan, A. (2010;2011;2014;) (14) and Max Kleiber. (2013) (12).

Whereas, the anaerobic ATP (Adenosine Triphosphate) production system is the first source of energy in the body, even where the direct ATP of the muscles is consumed by the formula $(\mathrm{ATP} \rightarrow \mathrm{ADP}+\mathrm{Pi}+$ Energy), and continues for a period not exceeding (3s).

Then the body moves to the next system of energy production systems, which is the formation of ATP by phosphocreatine, and this is done through the equation (ADP + PC $\rightarrow$ ATP $+C$ ), which lasts about ( $30 \mathrm{w}$ ) of muscle work, and this system is characterized by the very rapid production of the ATP is necessary to supply the body with the energy needed to perform the two movements, but one of the disadvantages of this system is the consumption of a large amount of glycogen to produce the ATP as it consumes about (180 grams) of glycogen to produce ( 3 mol of ATP). This is what caused the consumption of higher caloric intake than the endurance test.

And that is, on the contrary, in the endurance test, which lasts about $(120 \mathrm{w})$. Therefore, the body relies on energy production on the Lactic Acid System, a system that produces very large calories but is slowly consumed. Through this system, a whole glycogen molecule can produce about (39 moles of ATP). This system defects the appearance of fatigue as a result of the 
accumulation of acetic acid in the muscles, which may cause a decrease in the player's speed, which affects the energy expended as the energy is calculated by the formula $\left(\mathrm{KE}=1 / 2 \mathrm{~m} \cdot \mathrm{v}^{2}\right)$.

This means that the accumulation of lactic acid resulting from the body's transition to the lactic acid system for energy production has caused a decrease in the energy expended and the work is done, and thus this, in turn, led to a decrease in the calories consumed, according to the formula ( 1 calorie $=4.184$ joule $)$ which shows the direct relationship between joules and calories.

\section{7/0 Conclusions}

Within the limits of the study objectives, hypotheses, data used and the results presented, the researcher concludes the following:

- The total calorie consumed in physical tests. Admission to the Kingdom is about (740 Cal) and in Egypt (826.21 Cal)

- The total amount of work spent and the energy expended in physical tests. Admission to the Kingdom is about (10826.76 Joules) and in Egypt (7,739.97 Joules).

- the total power exerted in physical tests, admission to the Kingdom is about $(659.10$ Joules per second) and in Egypt (430.36 Joules per second)

- There is no difference in the arrangement of physical tests according to the calorie consumption between Egypt and Saudi Arabia except inability and agility there was a change between them.

- There is no difference in the arrangement of physical tests according to the work done and the energy spent, except inability and agility there was a change between them.

- There is a difference in the arrangement of physical tests according to the ability made between Egypt and the Kingdom.

\section{8/0 Recommendations:}

In light of the results of the study results, the researcher recommends the following:

- Conducting studies on admission tests between international colleges according to the Shanghai classification and comparing them with Arab universities.

- Re-design acceptance tests in the field of physical education, taking into account the variables under study.

- Complete the study dimensions by specifying the ability, work, energy, and calories in the skill tests.

- Conducting a qualification training program based on the results of the study for those applying for admission tests in colleges and departments of physical education.

- Calories are announced before every physical test.

- Providing intermission breaks between tests commensurate with the amount consumed for hospitalization calories and restoring the capacity of the energy production system used in the next test.

- Providing nutritional advice before applying for admission tests based on the results of the study on the caloric value variable.

\section{9/0 References:}

1- Bagchi, D., Nair, S., \& Sen, C. K. (2013). Nutrition and enhanced sports performance: Muscle building, endurance, and strength (1st ed.). US: Academic Press.

2- Bartlett, R. (1999). Sports Biomechanics: Reducing Injury and Improving Performance. Routledge. 
3- Bartlett, R. (2007). Introduction to sports biomechanics: Analyzing human movement patterns. London: Taylor and Francis. doi:10.4324/9780203462027

4- Bartlett, R., \& Payton, C. (2007; 2008). Biomechanical evaluation of movement in sport and exercise: The British association of sport and exercise sciences guidelines. England; United Kingdom; Routledge.

5- D,Gordon E,Rbertson, Gary kamen, Graham E,Caldwell, Joseph Hamil, SaundersN,Whittlesey: 2004, : Research Methods in Biomechanics , Human Kinetics publisher ; Champaign

6- Daries, H. (2012). Nutrition for sport and exercise: A practical guide (1st ed.). GB: WileyBlackwell.

7- Haff, G. G., Antoni, J., Greenwood, M., Kalman, D., Stout, J. R., \& Willoughby, D. S. (2008). Essentials of sports nutrition and supplements (1. Aufl. ed.) Humana Press.

8- Hany Abdul Aziz Saleh. (2016). Speed loss analysis during Illinois agility run test in light of some Bio-kinematics parameters, Assiut Journal of Sport Science and Arts, Vol. 3

9- Knudson, D. (2007). Fundamentals of biomechanics. Boston: Springer.

10- Kreider, R., Bendich, A., Antonio, J., Kalman, D., Willoughby, D. S., Haff, G. G., Greenwood, M. (2009;2008;). Essentials of sports nutrition and supplements. Totowa, NJ: Humana Press. doi:10.1007/978-1-59745-302-8

11- Marieb, E. N. (2016). Essentials of human anatomy \& physiology. San Francisco, CA: Pearson/Benjamin Cummings.

12- Max Kleiber. (2013). Calories and Joules, Journal of nutrition, United State of America.

13- McArdle, William D., Katch, Frank I.Katch, Victor L. (2010) Exercise physiology :nutrition, energy, and human performance Baltimore, MD : Wolters Kluwer Health/Lippincott Williams \& Wilkins,

14- McTiernan, A. (2010;2011;2014;). Physical activity, dietary calorie restriction, and cancer (1st ed.). New York, NY: Springer. doi:10.1007/978-1-44197551-5

15- Medical biochemistry E-book (2018). (Fifth ed.). GB: Elsevier.

16- Nestle, M., \& Nesheim, M. (2012). Why calories count: From science to politics (1st ed.). Berkeley: University of California Press. doi:10.1525/j. ctt7zw2qr

17- Pascolo, P. B. (2014). Biomechanics and sports: Proceedings of the XI winter universals 2003. Vienna: Springer Wien.

18- Payton, C. (Ed.), Burden, A. (Ed.). (2018). Biomechanical Evaluation of Movement in Sport and Exercise. London: Routledge,

19- Shamus, E. editor, \& Shamus, J. editor. (2017). Sports Injury Prevention \& Rehabilitation. McGraw-Hill Education LLC.

20- W. W. HAWKINS. (2013). The Calorie, The Joule, Canadian Journals of Research, National Research Council of Canada, Ottawa, Canada K1A OR6 